\title{
Cardiovascular Effects in Childhood Cancer Survivors Treated with Anthracyclines
}

\author{
Vivian I. Franco, ${ }^{1}$ Jacqueline M. Henkel, ${ }^{1}$ Tracie L. Miller, ${ }^{1,2}$ and Steven E. Lipshultz ${ }^{1,2,3}$ \\ ${ }^{1}$ Division of Pediatric Clinical Research, Department of Pediatrics, University of Miami Miller School of Medicine, \\ Medical Campus-BCRI-D820, 1580 NW 10th Avenue, 5th Floor, Miami, FL 33136, USA \\ ${ }^{2}$ Holtz Children's Hospital of the University of Miami/Jackson Memorial Medical Center, Sylvester Comprehensive Cancer Center, \\ Miami, FL 33136, USA \\ ${ }^{3}$ Department of Pediatrics (D820), University of Miami Miller School of Medicine, P.O. Box 016820, Miami, FL 33101, USA
}

Correspondence should be addressed to Steven E. Lipshultz, slipshultz@med.miami.edu

Received 15 October 2010; Accepted 15 December 2010

Academic Editor: Jean-Bernard Durand

Copyright (C) 2011 Vivian I. Franco et al. This is an open access article distributed under the Creative Commons Attribution License, which permits unrestricted use, distribution, and reproduction in any medium, provided the original work is properly cited.

\begin{abstract}
Anthracyclines are commonly used to treat childhood leukemias and lymphomas, as well as other malignancies, leading to a growing population of long-term childhood cancer survivors. However, their use is limited by cardiotoxicity, increasing survivors' vulnerability to treatment-related complications that can markedly affect their quality of life. Survivors are more likely to suffer from heart failure, coronary artery disease, and cerebrovascular accidents compared to the general population. The specific mechanisms of anthracycline cardiotoxicity are complex and remain unclear. Hence, determining the factors that may increase susceptibility to cardiotoxicity is of great importance, as is monitoring patients during and after treatment. Additionally, treatment and prevention options, such as limiting cumulative dosage, liposomal anthracyclines, and dexrazoxane, continue to be explored. Here, we review the cardiovascular complications associated with the use of anthracyclines in treating malignancies in children and discuss methods for preventing, screening, and treating such complications in childhood cancer survivors.
\end{abstract}

\section{Introduction}

Cancer is diagnosed in more than 12,000 children in the United States every year [1]. Over the past 25 years, the 5- and 10-year survival rates for childhood cancers have substantially improved, from less than $50 \%$ in the 1970 s to almost $80 \%$ today $[2,3]$. Some of this improvement comes from the use of anthracycline chemotherapeutic agents, which are widely used to treat childhood leukemias and lymphomas, as well as other malignancies. Their use has helped create a growing population of long-term childhood cancer survivors of more than 325,000 in the United States alone [4]. However, this growing population of survivors is at a substantial risk for treatment-related complications that can markedly affect their quality of life. Increasingly, survivors and their clinicians are realizing the importance of continuous monitoring long after their cancer treatment has been completed.
Within the first 30 years after diagnosis, $75 \%$ of childhood cancer survivors will suffer from a chronic health condition [5]. Recent 5-year estimates indicate that the leading non-cancer-related cause of morbidity and mortality in long-term survivors of childhood cancer is cardiovascularrelated disease [5-10]. Survivors are 8 times more likely than the general population to die from cardiovascular-related disease, and compared to sibling controls, they are 15 times as likely to suffer from heart failure (HF), more than 10 times as likely to have coronary artery disease, and more than 9 times as likely to have had a cerebrovascular accident during the first 30 years after cancer diagnosis [5].

Anthracyclines, such as doxorubicin, are among the leading causes of these cardiovascular events. The cardiotoxic nature of anthracyclines, coupled with their widespread use, may explain the large impact they have made on survivor morbidity and mortality [11]. Childhood cancer survivors exposed to anthracyclines are at a significantly increased 
risk of $\mathrm{HF}$, and this risk increases as the cumulative dose increases; 30 years after diagnosis, more than $7.5 \%$ will have experienced HF [7]. The risks of cardiac events persist up to 45 years beyond treatment and are the second most common cause of death, after secondary malignancy [12]. Cardiotoxicity from childhood cancer treatments is a cause for heart transplantation in young adults [13]. In addition to clinical outcomes, detailed cardiac evaluations have shown that more than half of anthracycline-exposed childhood cancer survivors have subclinical cardiac abnormalities, including decreased left ventricular (LV) mass and wall thickness, increased LV afterload, and decreased LV contractility [14].

The severity of the cardiotoxic effects of anthracyclines vary and are categorized by time of onset as acute, occurring during or immediately after treatment, early, occurring within 1 year of exposure, and late, occurring 1 or more years after initial exposure (Table 1) $[11,15]$. Severe cardiotoxicity, during or shortly after treatment, is strongly associated with HF later in life, despite an initial asymptomatic interval. In a followup study of long-term survivors of childhood cancer who were treated with anthracyclines and who experienced acute HF, all had a temporary recovery though nearly half of these patients later had recurrent HF [14]. Understanding the early- and late-onset cardiovascular complications of long-term survivors of childhood cancer is important for oncologists, cardiologists, and other health care providers involved in the care of such patients, not only after cancer treatment but also when selecting treatments at the time of diagnosis.

Here, we review the cardiovascular complications associated with the use of anthracyclines in treating malignancies in children and discuss methods for preventing, screening, and treating such complications in childhood cancer survivors.

\section{Anthracyclines and Mechanisms of Cardiotoxicity}

Anthracyclines are commonly used to treat a variety of solid and hematologic tumors in both adults and children. However, because they have clinically relevant dosedependent cardiotoxicity, lower doses are used in treating childhood cancer [18, 19]. Anthracyclines express their anticancer effects through two major mechanisms: (1) their intercalation between base pairs of DNA prevents cancer cells from replicating and (2) their inhibition of topoisomeraseII activity prevents the uncoiling process of DNA that is necessary for replication and transcription.

However, the specific mechanisms of anthracycline cardiotoxicity are complex and, despite decades of research, remain unclear. The oxidative stress hypothesis is among the most widely studied and accepted cellular mechanism thought to cause cardiotoxicity [20-23]. Once administered, anthracyclines are believed to enter cells through passive diffusion, where they can reach intracellular concentrations several hundred times higher than that in extracellular compartments. Once inside the cell, anthracyclines may form complexes with intracellular iron, leading to the production of free radicals, which can cause DNA damage and lipid peroxidation. The damage caused by free radicals, and by reactive oxygen species (ROS), can eventually lead to cell death and larger-scale organ damage.

Why the heart is particularly vulnerable to oxidative stress caused by anthracyclines is not clear, but the abundance of mitochondria found in cardiomyocytes [5] may be involved. Increasingly, the importance of mitochondria as key mediators of anthracycline-induced cardiotoxicity has been reported [24]. Cardiolipin, a phospholipid found in high concentrations on the inner cell membrane of cardiac mitochondria, has a high affinity for anthracyclines. This affinity allows increased concentrations to enter cardiac mitochondria $[25,26]$, which may impair membrane stability or lead to mitochondrial DNA damage by intercalation. Anthracycline effects on the mitochondria may also impair the cell's ability to produce energy and to handle the added oxidative stress of cancer and its treatments [21, 27-29]. In addition, one of the heart's key antioxidants, glutathione peroxidase, is depleted in the presence of anthracyclines [30].

Several other mechanisms have been suggested for anthracycline cardiotoxicity, including the induction of apoptosis, abnormal creatine kinase activity, the production of vasoactive amines, the formation of toxic metabolites, upregulation of nitric oxide synthetase, and the inhibition of transcription and translation [31-33]. Anthracyclines cause uncoupling of the electron transport chain, which creates highly reactive oxygen species, and can impair oxidative phosphorylation and adenosine triphosphate (ATP) synthesis [24]. Anthracyclines can also impair mitochondrial calcium homeostasis, leading to the loss of stability of the mitochondrial membrane, decreased ATP, and cell death.

In addition, several other changes have been observed in anthracycline-exposed cardiomyocytes, for which the underlying mechanisms have yet to be fully explained. These changes include depleted cardiac stem cells [34], impaired DNA synthesis [35], impaired cell signaling that triggers cell death [36], altered gene expression [37], inhibited calcium release from the sarcoplasmic reticulum [38], impaired formation of the protein titin in sarcomeres [39], and impaired mitochondrial creatine kinase activity and function [40]. None of these findings, however, are necessarily completely dependent or independent of an oxidative stress pathway. The fact that many of these subcellular consequences continue to progress for weeks after anthracycline exposure may provide insight into the mechanisms of chronic cardiomyopathy [41].

Finally, understanding cardiovascular cell signaling proteins may prove useful by clarifying both the pathway of toxicity and the early detection of anthracycline-induced cardiotoxicity. Because of the synergistic cardiotoxic potential of anthracyclines and the ErbB2 antibody, trastuzumab, interest in the role of neuregulin (NRG-1) is growing. Neuregulin is a growth factor that is an endogenous ligand for the protein ErbB2 and is possibly involved in a signaling pathway that regulates sarcomere functioning [33]. Neuregulin levels are decreased with anthracycline use, suggesting a potential mechanism of toxicity. However, this decrease has not 
TABLE 1: Characteristics and course of anthracycline-induced cardiotoxicity [15].

\begin{tabular}{llll}
\hline Characteristics & Acute cardiotoxicity & $\begin{array}{l}\text { Early-onset, chronic progressive } \\
\text { cardiotoxicity }\end{array}$ & $\begin{array}{l}\text { Late-onset, chronic progressive } \\
\text { cardiotoxicity }\end{array}$ \\
\hline Onset & $\begin{array}{l}\text { Within the first week of } \\
\text { anthracycline treatment } \\
\text { Risk factor dependence }\end{array}$ & $\begin{array}{l}<1 \text { year after the completion of } \\
\text { anthracycline treatment }\end{array}$ & $\begin{array}{l}\geq 1 \text { year after the completion of } \\
\text { anthracycline treatment }\end{array}$ \\
Clinical features in adults & $\begin{array}{l}\text { Transient depression of } \\
\text { myocardial contractility }\end{array}$ & Yes & Dilated cardiomyopathy \\
Clinical features in children & $\begin{array}{l}\text { Transient depression of } \\
\text { myocardial contractility }\end{array}$ & $\begin{array}{l}\text { Restrictive cardiomyopathy and/or } \\
\text { dilated cardiomyopathy }\end{array}$ & $\begin{array}{l}\text { Restrictive cardiomyopathy and/or } \\
\text { dilated cardiomyopathy }\end{array}$ \\
Course & $\begin{array}{l}\text { Usually reversible on } \\
\text { discontinuation of anthracycline }\end{array}$ & Can be progressive & Can be progressive \\
\hline
\end{tabular}

From Adams et al. [15]. Reprinted with permission from John Wiley \& Sons, Inc.

${ }^{a}$ Data from Giantris et al. [16], and Grenier and Lipshultz [17].

been clearly associated with serum and echocardiographic markers of cardiac dysfunction [42].

\section{Risk Factors for Anthracycline-Related Cardiac Abnormalities}

Not all children exposed to anthracyclines experience cardiac abnormalities, and the clinical severity of the abnormalities that do occur varies greatly between individuals. Hence, determining the factors that may increase susceptibility to the cardiotoxic effects of anthracyclines is of great importance. First, ascertaining which patients are most likely to experience cardiotoxicity can guide treatment, especially as long-term health becomes a more prominent treatment focus. Second, identifying risk factors may help to determine the mechanisms directly responsible for cardiac damage and potentially lead to novel strategies for cardioprotection and treatment. Third, risk stratification may help guide the efficient use of followup screening [22].

One of the main risk factors for anthracycline cardiotoxicity is high cumulative dose. Since the 1970s, studies have shown that higher cumulative doses of anthracyclines [43] and higher infusion rates are risk factors for anthracycline cardiotoxicity $[10,19]$. The strong association between cumulative anthracycline dose and cardiotoxicity appears to be more important with increasing time from treatment $[44,45]$. This relationship was revealed in a study of nearly 15,000 long-term survivors of childhood cancer treated with anthracyclines who described their cardiac health at up to 30 years after cancer treatment (Figure 1) [7]. Other known risk factors for anthracycline cardiotoxicity include younger age at treatment, female sex, the use of concomitant cardiotoxic therapies (such as mediastinal radiation), increasing time since treatment, cardiac injury, as indicated by elevations of serum cardiac troponin-T (cTnT), neurohormonal activation of cardiac myocytes in response to pressure and stress, as indicated by elevations of $\mathrm{N}$-terminal probrain natriuretic peptide (NT-proBNP), during anthracycline therapy, and HF during anthracycline therapy $[5,10,14,19,28,45]$.

Although not completely understood, genetic predisposition may also be an important factor in determining the risk of anthracycline cardiotoxicity [46-48]. Genetic polymorphisms may alter membrane permeability, antioxidant capacity, or metabolism that favors the creation of cardiac damage. Hereditary hemochromatosis, a genetic disorder prevalent in individuals of European descent that can lead to iron overload, is of particular interest because doxorubicin's cardiotoxic effects depend, at least in part, on its interaction with iron. In mice, Hfe deficiency, the defective gene in hereditary hemochromatosis, increases the susceptibility to doxorubicin-induced cardiotoxicity, including mitochondrial degradation and increased mortality, when compared to that found in wild-type mice [49]. This fact suggests that genetic mutations related to defects in iron metabolism may contribute to cardiotoxicity in humans although there is currently no literature on the effect in humans. The concept of genetic predisposition as a risk factor for cardiotoxicity is further supported by findings of greater cardiac susceptibility in patients with trisomy 21 and black race $[50,51]$.

Despite the identification of these population-based risk factors, determining the risk for a specific patient is still difficult. Therefore, it is important that all children who receive anthracycline therapy be followed closely, both during and after treatment for cardiotoxicity. As a guide, the "Long-term Follow Up Program Resource Guide" [52], developed by Children's Oncology Group's Nursing Discipline Committee in collaboration with the Late Effects Committee, provides recommendations for screening and management of late effects of therapeutic exposures used during treatment for pediatric malignancies.

\section{Monitoring Long-Term Cancer Survivors}

4.1. Biomarkers. Although identifying multiple risk factors has helped to characterize groups at high risk for cardiac injury, both tolerance of chemotherapy and predisposition to cardiac damage still vary substantially between patients. This difference has led to an increasing interest in the use of monitoring serum biomarkers as a means of evaluating cardiotoxicity during and after treatment with anthracyclines. 


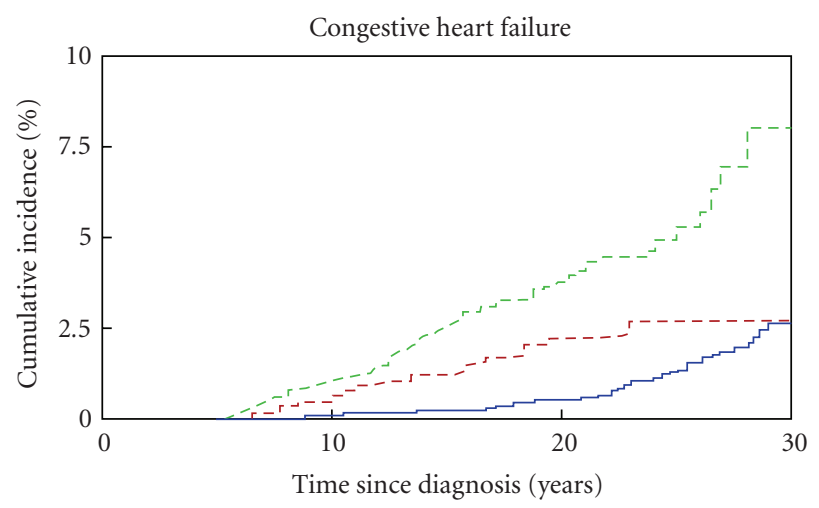

(a)

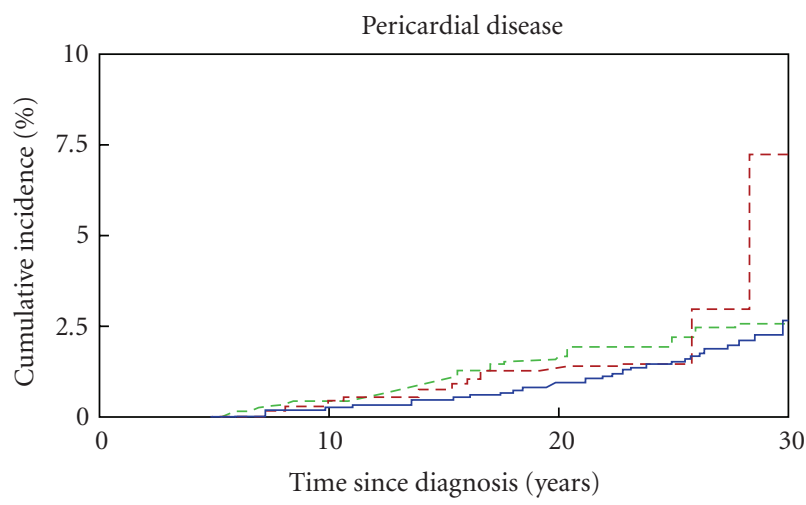

(b)

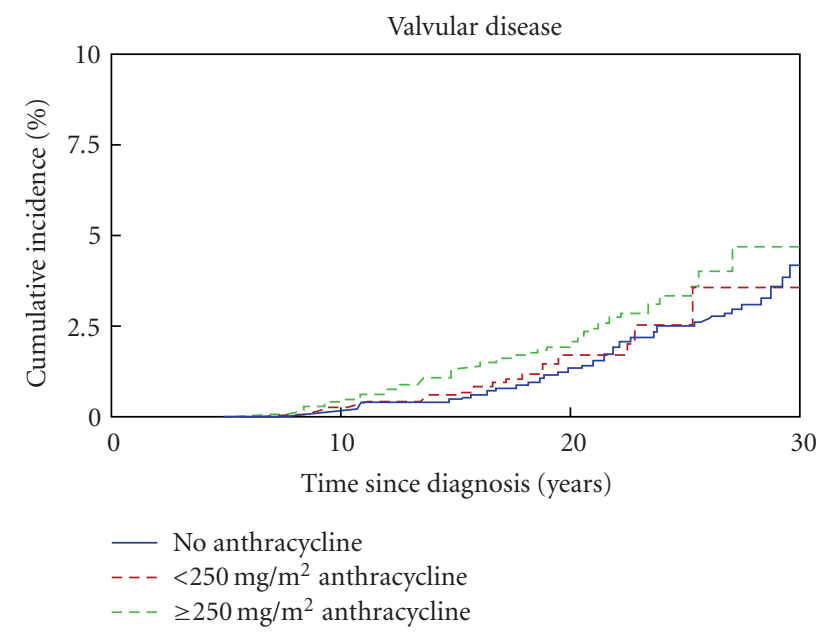

(c)

Figure 1: Cumulative incidence of cardiac disorders among childhood cancer survivors by anthracycline dose. From Mulrooney et al. [7]. Reprinted with permission from BMJ Publishing Group, Ltd.

4.1.1. Serum Cardiac Troponins. Elevations in cardiac troponin-T and I (cTnT and cTnI) accurately indicate cardiac damage, and their presence in serum in any detectable amount may indicate irreversible cellular necrosis $[45,54$, 55]. Cardiac troponin- $T$ is a cardiac-specific isoform that is present in cardiac myocytes in both the contractile unit and the cytoplasm. Serum cardiac troponins are widely used in diagnosing and managing ischemic heart disease in adults and also provide valuable clinical information in many other types of cardiac damage in children [56].

Initial investigations in animal models found dosedependent $c \operatorname{TnT}$ elevations in response to doxorubicin administration, elevations that were related to the severity of histopathologic findings in cardiac tissue. This relationship is consistent with the hypothesis that anthracyclines damage cardiomyocytes, leading to the release of intracellular cTnT into the circulation [57].

The Dana-Farber Cancer Institute childhood acute lymphoblastic leukemia (ALL) consortium protocol 95-001 study found that elevated serum cTnT levels during the first 90 days of anthracycline therapy were significantly associated with reduced LV mass and LV end-diastolic posterior wall thickness as measured by echocardiography 4 years later $[58,59]$.

The cardiac contractile protein, cTnI, when present in the serum, is related to LV dysfunction and increased cardiovascular risk in adults receiving high-dose chemotherapy $[54,55]$. These findings provide evidence of the value of serum troponin measurements in childhood cancer patients receiving anthracyclines.

4.1.2. Serum NT-proBNP. N-terminal probrain natriuretic peptide is produced during the cleavage of proBNP, a prohormone released from the cardiac ventricles in response to pressure overload and stretching $[60,61]$. Chronic elevations in NT-proBNP indicate increased ventricular wall stress, in association with pressure overload and elevated diastolic pressure $[62,63]$.

The aforementioned Dana-Farber Cancer Institute protocol 95-001 study also assessed serum NT-proBNP measurements during and after therapy as possible predictors of cardiac damage. Elevations in NT-proBNP during the first 90 days of therapy were associated with an abnormal LV thickness-to-dimension ratio 4 years later, suggesting 


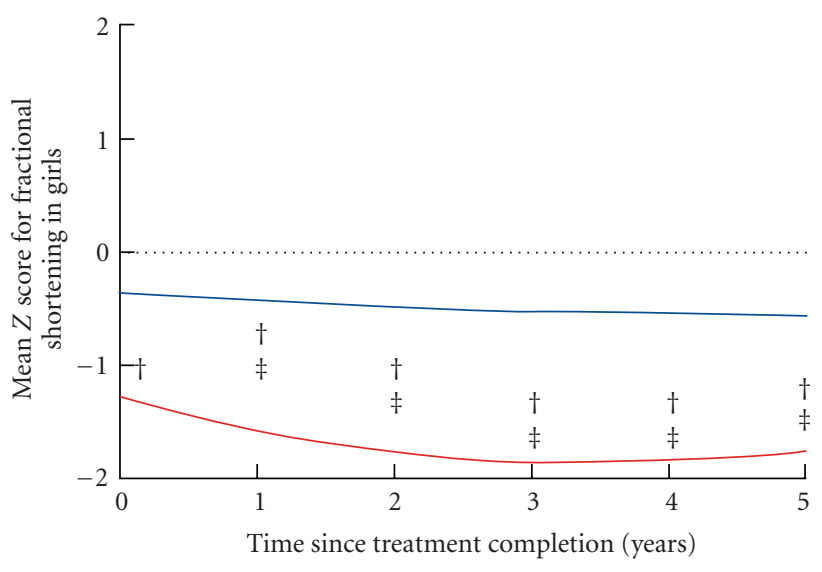

(a)

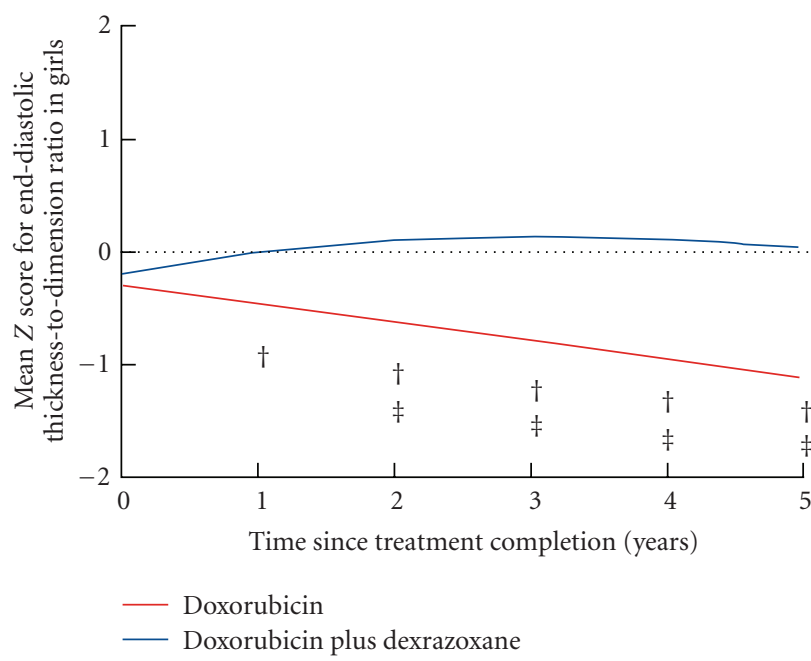

(c)

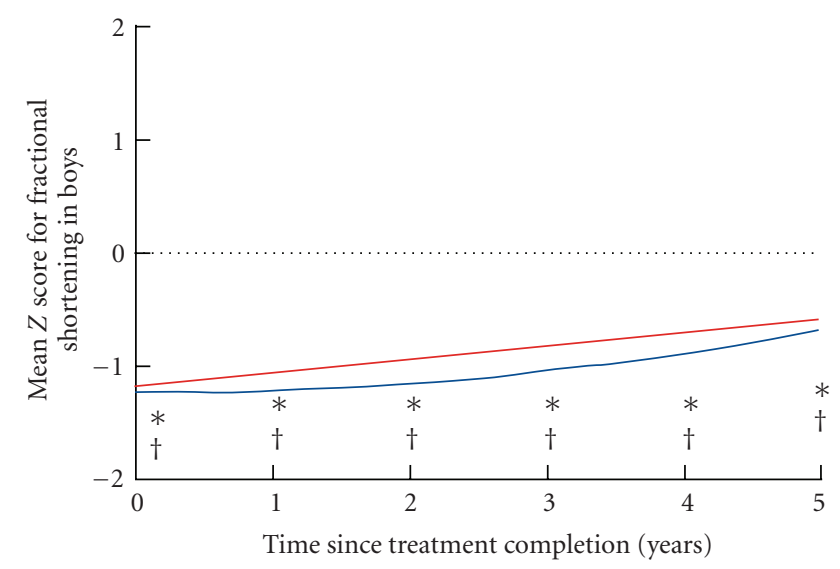

(b)

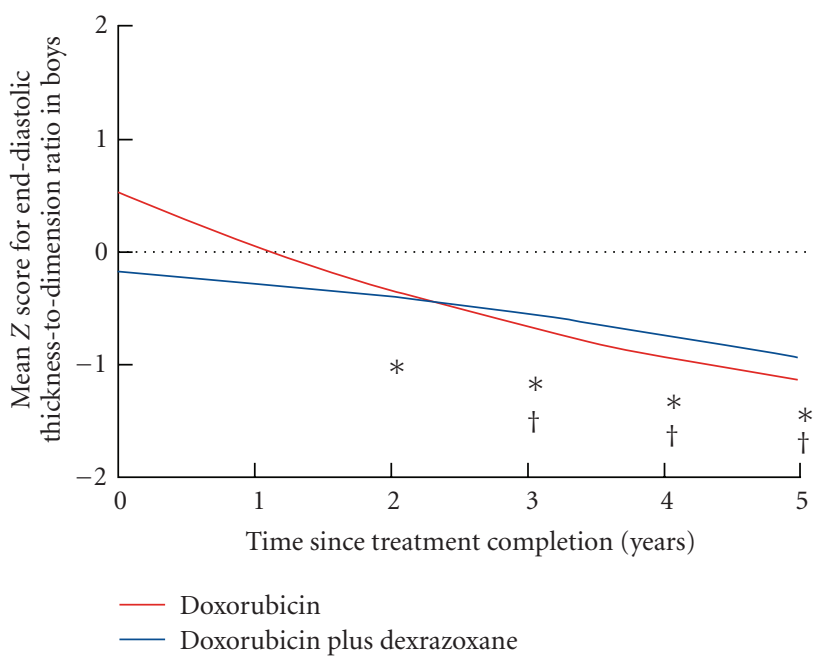

(d)

FIgURE 2: Mean left ventricular echocardiographic $Z$ scores in boys and girls $(n=134)$. Plots are adjusted for age; * $P \leq .05$ for comparison of the mean $Z$ score of the doxorubicin plus dexrazoxane group with zero; ${ }^{\dagger} P \leq .05$ for comparison of the mean $Z$ score for the doxorubicin group with zero; ${ }^{\ddagger} P \leq .05$ for comparisons of mean $Z$ scores between the doxorubicin and doxorubicin plus dexrazoxane groups. From Lipshultz et al. [53]. Reprinted with permission from Elsevier.

pathologic ventricular remodeling. Additionally, a higher percentage of children had elevated levels of NT-proBNP than had elevated levels of cTnT before, during, and after treatment. This difference suggests that NT-proBNP may detect cardiac stress before any irreversible cell damage and death occurs, which may help identify children early in therapy who are at increased risk of eventual anthracyclinerelated cardiac abnormalities [59].

4.1.3. High-Sensitivity C-Reactive Protein. As a global inflammatory marker and a critical component of the immune system, high-sensitivity C-reactive protein (hsCRP) is widely used to assess patient health [64]. Systemic inflammation is associated with increased rates of cardiovascular disease in adults and may also be involved with the mechanisms underlying anthracycline-related cardiotoxicity and pediatric cardiomyopathy [65]. As such, elevations in hsCRP may be a strong indicator of cardiac stress [66].
Despite a small sample size, one study of 19 children with HF divided into three groups based on symptom severity found that serum hsCRP levels were associated with decreased LV function and discriminated between the different groups of symptom severity [65]. Another study of 156 survivors of childhood ALL showed that survivors had significantly elevated levels of hsCRP when compared to levels in sibling controls [67]. These findings have encouraged further research on the use of serum hsCRP measurements collected during therapy as potential predictors of late cardiac effects. Serum hsCRP may prove to be a valuable screening tool for identifying long-term survivors at increased risk of subsequent cardiac disease.

4.2. Nanoparticle-Capture Mass Spectrometry. The ability to identify heart-derived tissue proteins associated with myocardial injury that can be detected before marked elevations in CTnT could have profound implications on 
earlier detection and clinical monitoring for doxorubicin cardiotoxicity. One pilot study using nanoparticle-mass spectrometry identified several candidate protein biomarkers previously implicated in cardiac dysfunction, remodeling, fibrosis, and hypertrophy [68]. Identification of these candidate biomarkers have the potential to increase the predictive value of more routinely used markers, such as cTnT, for earlier detection of cardiac damage, before irreparable damage and loss of cardiomyocytes occur. However, due to the small limited sample size, further studies evaluating the efficacy of nanoparticle-mass spectrometry may advance this novel diagnostic approach.

4.3. Echocardiography. Several detailed echocardiographic studies in 115 long-term childhood ALL survivors treated with doxorubicin have been conducted to better determine the long-term cardiac status of these patients [14, 69, 70]. These studies, ranging from 6 to 12 years of followup after treatment, have documented a persistent and progressive restrictive-like cardiomyopathy in long-term childhood cancer survivors treated with anthracyclines $[14,69,70]$. The restrictive cardiomyopathic-like nature of anthracycline cardiotoxicity may be of great clinical importance in that it suggests theories and treatments derived from studies of dilated cardiomyopathy may be of limited value in understanding anthracycline cardiotoxicity throughout life [71]. The findings of abnormal LV structure and function, as well as a restrictive-like cardiomyopathic pattern, are consistent with those of other long-term followup studies conducted in other groups of anthracycline-treated childhood cancer survivors [72-74].

\section{Preventing Anthracycline-Induced Cardiotoxicity}

5.1. Anthracycline Dosage. Treatment protocols using lower doses of anthracyclines have reduced the incidence of acute cardiac complications to less than $1 \%$ although chronic LV dysfunction is still a major clinical concern $[50,53]$. In the 1970s, before the association between higher cumulative doses of anthracyclines and the greater risk of cardiotoxicity was known, clinical trials administered cumulative doxorubicin doses greater than $400 \mathrm{mg} / \mathrm{m}^{2}$ to children with ALL. Lipshultz et al. found that patients who received such high cumulative doses experienced clinically important, progressive LV effects that continued even decades after the completion of doxorubicin treatment $[14,69,70]$. On the basis of this experience, cumulative doses of doxorubicin administered to children and adolescents with ALL were reduced in the 1980s such that high-risk children received a cumulative dose of no more than $360 \mathrm{mg} / \mathrm{m}^{2}$, and standardrisk children received a relatively low cumulative dose of no more than $60 \mathrm{mg} / \mathrm{m}^{2}[58,75]$. Followup of the high-risk patients suggested that some risk of delayed LV abnormalities remained, although the frequency of overt HF was much lower $[14,69,70]$.

In the 1990s, analysis of the combined results of the Dana-Farber Cancer Institute's long-term survivors and those from patients treated in Denmark revealed that after a median followup of 8.1 years, the risk of LV abnormalities was lower in patients who received no more than $300 \mathrm{mg} / \mathrm{m}^{2}$ than it was in those who received more than $300 \mathrm{mg} / \mathrm{m}^{2}$ of doxorubicin [19]. On the basis of those results, the cumulative doxorubicin dose for high-risk ALL patients on the Dana-Farber Cancer Institute Protocol 95-001 were further reduced to $300 \mathrm{mg} / \mathrm{m}^{2}$.

5.2. Liposomal Anthracyclines. Structural modifications of anthracyclines have been considered as possible cardioprotection strategies. Of the structural modifications of anthracyclines, liposome-encapsulated anthracyclines are possibly the most promising cardioprotectant. Liposomeencapsulated anthracyclines escape the leaky capillary system of tumor sites and as such remain concentrated there, in the interstitial fluid. They are also less likely to escape the tight capillary junctions of the heart. This ability to reduce the plasma levels of free doxorubicin is thought to be the source of the reduced cardiotoxicity provided by liposomal formulations of anthracyclines [76]. Although studies of liposomalencapsulated anthracyclines are limited in children, biopsies have confirmed that these anthracyclines have a lower early cardiotoxicity than conventional anthracyclines [77], and studies by Marina et al. have helped to confirm their safety in children [78].

5.3. Treatment with Continuous Anthracycline Infusion. Because the cellular mechanisms underlying anthracycline cardiotoxicity are still not completely understood, it has been theorized that continuous infusion might provide some cardioprotective benefit by lowering peak serum levels of the drug [79]. This theory was supported by findings from observational studies in children that found higher dose rates to be associated with cardiotoxicity, independently of the effect of total dose [80]. In addition, in adults receiving anthracyclines, acute cardiotoxicity was diminished in protocols using continuous infusion [81]. On the basis of these findings, continuous infusion was incorporated into many pediatric protocols, despite a lack of evidence on its long-term cardioprotective efficacy $[44,82]$.

A randomized controlled trial of continuous (over 48 hours) doxorubicin infusion versus bolus doxorubicin infusion in 121 high-risk pediatric ALL cases found no cardiac-related benefit to using the continuous infusion after a median of 1.5 years after diagnosis [44]. Similar results were found after continued followup of this cohort at a median followup of 8 years [82]. In addition, several retrospective reviews reported no statistically significant differences in the echocardiographic characteristics of children with cancer 5 to 7 years after treatment with either continuous infusion (over 6 to 24 hours) or bolus infusion of anthracyclines $[79,80]$.

5.4. Treatment with Dexrazoxane. As mentioned above, anthracycline-related cardiotoxicity is likely related, at least in part, to the generation of ROS, which may be exacerbated by iron-dependent mechanisms [81]. This relationship has 
led to the investigation of several iron-chelating agents, such as dexrazoxane, for preventing anthracycline cardiotoxicity [81]. Dexrazoxane is an iron-chelating agent that inhibits the formation of anthracycline-iron complexes that generate toxic and highly charged ROS. However, other mechanisms independent of oxidative stress have been proposed as mediators in the cardioprotective effect of iron chelation [23], such as the mitigation of DNA damage caused by dexrazoxane [76]. This proposal has led to great interest in the use of dexrazoxane in children [83]. Dexrazoxane is currently recommended by the American Society of Clinical Oncology for preventing cardiotoxicity in specific adult cancer treatment protocols [81].

Fearing that the protection dexrazoxane provides to cardiomyocytes might extend to cancer cells as well and perhaps lead to increased rates of second malignancies, some investigators have been reluctant to use dexrazoxane. Although such a relationship was previously reported [84], but questioned $[85,86]$, in a pediatric Hodgkin lymphoma trial, no association between dexrazoxane and second malignancies has been found [87].

A randomized controlled trial of dexrazoxane in children with ALL treated with doxorubicin used serial cTnT samples taken during therapy to measure cardiac damage [57]. Of the 82 children who received doxorubicin plus dexrazoxane, significantly fewer had cTnT elevations when compared with the 76 children who received doxorubicin alone. The difference between groups became even greater over the course of treatment. After 6 to 8 months, almost $50 \%$ of those treated with doxorubicin alone had an elevated cTnT level, as opposed to less than $10 \%$ of those treated with doxorubicin plus dexrazoxane. A recent followup report of this group at a median of 8.7 years found that event-free survival did not differ significantly between the two groups [53] and that there was no increased risk of recurrence or second malignant neoplasms $[53,87]$. These findings show that dexrazoxane can provide long-term cardioprotection without hindering the efficacy of doxorubicin.

Serial echocardiographic measurements during the 4 years after this trial have also been reported [53]. Children treated with doxorubicin plus dexrazoxane had progressively less decreased LV fractional shortening and greater LV mass and LV wall thickness over time. Most recently, the protective effects of dexrazoxane reported in this trial appear to be sex related [53], which is consistent with recent findings from animal studies [88]. Females showed the greatest protective effect from dexrazoxane therapy, while males receive did not receive such benefit (Figure 2) [53]. These findings further highlight that there is still much to learn about the mechanisms underlying such differences $[53,89]$ although sex-related differences in the transport and clearance of doxorubicin have been reported [90, 91], as has dexrazoxane cardioprotection against the sex-related hormone, testosterone [92].

The protective effect of dexrazoxane against anthracycline cardiotoxicity is further supported by studies of childhood cancers other than leukemia [81, 83]. However, research is needed to fully understand the subtle risks associated with the use of dexrazoxane, what methods of dexrazoxane administration are most efficient, and what doses are necessary to achieve adequate protection.

\subsection{Traditional Cardiovascular Disease Risk Factors. With} more extended followup, the true incidence of chronic HF in long-term childhood cancer survivors treated with anthracyclines may exceed the reported $1 \%$ to $16 \%$ range [44, 93]. Chronic anthracycline cardiotoxicity is not only evident as symptomatic LV dysfunction, it also frequently manifests as subclinical abnormalities in LV structure and function. In some cases, these subclinical changes may progress to HF and cardiac death. Such effects may also leave long-term childhood cancer survivors more vulnerable to future nonanthracycline-related cardiovascular insults.

Long-term childhood cancer survivors, like the general population, may have one or more of the traditional risk factors for atherosclerosis, which could provide an additive risk of future cardiovascular complications beyond that directly related to cancer therapies. Obesity, physical inactivity, tobacco use, and diabetes mellitus are among the most commonly examined traditional modifiable atherosclerotic risk factors. An improved understanding of the lifetime cardiovascular risk associated with these factors in long-term childhood survivors may help guide treatment and predict any potential additional cardiovascular risk of specific cancer therapies, such as the use of anthracyclines [94].

5.5.1. Obesity. In the United States, childhood obesity rates have increased to where it has now become epidemic $[95,96]$. Less than $5 \%$ of 12 -to-19-year-olds were overweight in the late 1960s, while almost $17 \%$ were overweight by the year 2008 [96]. This report also shows that almost 32\% of children and adolescents between 2 to 19 years old are at risk of overweight. One study showed that almost $80 \%$ of obese 10 to-14-year-olds who had an obese parent were obese as adults [97]. This relationship raises two main concerns: (1) childhood overweight and obesity are associated with poor health outcomes, such as coronary artery disease, hypertension, and diabetes [98] and (2) childhood obesity is strongly associated with adult obesity, which is associated with an increased risk of atherosclerotic disease and death. The American Heart Association's Childhood Obesity Research Summit concluded that: "Obesity contributes to a significant burden in terms of chronic diseases, rising healthcare costs, and, most importantly, disability and premature death. It appears that this burden will increase in the future [99]."

Studies of obesity in long-term survivors of childhood cancer have found similarly troubling trends suggesting that survivors may be at increased risk for obesity as a result of their cancer history. One study compared body fat between 170 pediatric cancer survivors and 71 sibling controls. This study found that more than one-third of survivors met the criteria for overweight or obese according to the body mass index (BMI), but this was no different than siblings. However, male survivors were found to have greater body fat and trunk fat compared to siblings, while no differences were found between female survivors and siblings [100]. 
TABLE 2: Areas for future research in anthracycline cardiotoxicity. ${ }^{\mathrm{a}}$

\begin{tabular}{|c|c|}
\hline Basic research & Clinical research \\
\hline $\begin{array}{l}\text { (1) Exploration beyond the oxidative stress hypothesis as } \\
\text { a primary mechanism of anthracycline cardiotoxicity }\end{array}$ & $\begin{array}{l}\text { (1) Reduction of anthracycline cardiotoxicity in clinical } \\
\text { practice }\end{array}$ \\
\hline (2) Implementation of long-term studies in animal models & (2) Identification of early signs of cardiac damage \\
\hline (3) Identification of predictive markers of cardiac damage & $\begin{array}{l}\text { (3) Educate clinicians: anthracycline-induced cardiotoxicity } \\
\text { can initially respond to cardiac medications }\end{array}$ \\
\hline $\begin{array}{l}\text { (4) Determination of the relative impact of different } \\
\text { mechanisms of myocardial damage }\end{array}$ & $\begin{array}{l}\text { (4) Determination of the cardiotoxicity of targeted and } \\
\text { combination therapies }\end{array}$ \\
\hline $\begin{array}{l}\text { (5) Exploration into the relationship between growth factors } \\
\text { and anthracyclines }\end{array}$ & $\begin{array}{l}\text { (5) Identification of a balance between cardiotoxicity with } \\
\text { clinical benefit }\end{array}$ \\
\hline $\begin{array}{l}\text { (6) Understanding drug interactions in new combination } \\
\text { therapies }\end{array}$ & (6) Definition of risks and benefits for subgroups of patients \\
\hline $\begin{array}{l}\text { (7) Assessment of the effects of anthracyclines on cardiac } \\
\text { development }\end{array}$ & $\begin{array}{l}\text { (7) Management of cardiac dysfunction in cancer survivors } \\
\text { treated with anthracyclines }\end{array}$ \\
\hline $\begin{array}{l}\text { (8) Assessment of the effects of anthracyclines on } \\
\text { non-myocyte cardiac cells }\end{array}$ & $\begin{array}{l}\text { (8) Specifications of dietary and exercise recommendations } \\
\text { for anthracycline-treated patients }\end{array}$ \\
\hline $\begin{array}{l}\text { (9) Assessment of risk-benefit factors in groups with } \\
\text { compounding risk factors for cardiomyopathy }\end{array}$ & $\begin{array}{l}\text { (9) Understanding the progression of anthracycline } \\
\text { cardiomyopathy: systolic versus diastolic heart dysfunction }\end{array}$ \\
\hline $\begin{array}{l}\text { (10) Determination of genetic predispositions to } \\
\text { anthracycline cardiotoxicity }\end{array}$ & $\begin{array}{l}\text { (10) Expansion of the use of dexrazoxane and liposomal } \\
\text { anthracyclines }\end{array}$ \\
\hline
\end{tabular}

a Data from Gianni et al. [23].

The largest report to date of nearly 8000 long-term survivors found that about $41 \%$ were either obese or overweight [100]. This study and others also found that despite a high prevalence of obesity, long-term survivors were not more likely to be obese than the general population although certain groups, such as survivors of ALL, were at increased risk of obesity [101, 102].

The idea that certain subgroups of long-term childhood survivors are at increased risk of obesity is supported by studies of those survivors exposed to cranial radiation. Many of these studies reveal treatment-related damage to the hypothalamic-pituitary axis, with subsequent growth hormone deficiency and eventual obesity. However, it should be noted that not all studies have found such a relationship and that other factors, such as obesity before diagnosis, may be more powerful predictors of obesity after treatment [103]. It is clear, though, that obesity is highly prevalent in survivors of all types of childhood cancer and may predispose this group to future health problems, especially atherosclerotic disease, which may be especially problematic for these patients who are less able to compensate for ischemic cardiac insults.

5.5.2. Physical Inactivity. Physical inactivity is associated with higher risk of cardiovascular disease as well as with other traditional atherosclerotic disease risk factors, such as insulin resistance and obesity. Physical activity is not only recommended by several medical associations, including the American Academy of Pediatrics, but guidelines have been created by several organizations, including the US Department of Health and Human Services [104, 105].

Physical inactivity appears to be more common in longterm childhood survivors than in the general population.
Miller et al. [102] reported that male survivors watched significantly more hours of television compare to siblings. They also found that increased television viewing hours was associated with higher BMI and percent body fat in male and female survivors of childhood cancer. A survey of nearly 10,000 long-term survivors of childhood cancer and 3,000 of their siblings revealed that survivors were more likely than their healthy siblings and the general population to report being physically inactive and being less likely to meet recommended physical activity guidelines [106]. This survey and others have found that some long-term childhood survivors may be unable to comply with these guidelines as a result of the physical limitations incurred by their cancer-related surgery or treatment-related cardiac damage. Hopefully, interventions that lead to appropriate and safe increases in the physical activity of long-term survivors may decrease risk of atherosclerotic disease and its associated negative health outcomes [107].

5.5.3. Tobacco Use. Cigarette smoking is a well-known major preventable risk factor for cardiovascular disease and allcause mortality among individuals in the general population. The increased rate of cardiovascular disease in smokers has been convincingly evident since the 1960s [108]. One systematic review of the health behaviors of long-term survivors found that most studies have reported lower rates of smoking in survivors relative to the general population although these rates are still high enough to be a concern and to warrant intervention [109].

Up to $17 \%$ of long-term childhood survivors in the United States are active smokers, compared to more than $20 \%$ of the general adult population $[110,111]$. The increased cardiovascular disease risk associated with 
smoking may be magnified in long-term survivors who may already have underlying cardiac abnormalities as a result of their malignancy and its treatment. Therefore, efforts aimed at smoking prevention and cessation in long-term childhood survivors are essential to improve long-term outcomes [112].

5.5.4. Insulin Resistance. The prevalence of insulin resistance and overt diabetes has risen steadily and parallels the rise in the prevalence of obesity and the decline in physical activity. In the United States today, almost $13 \%$ of adults aged 20 years or older have either diabetes or prediabetes, a prevalence that rose from $5.1 \%$ between 1988 and 1994 and to $7.7 \%$ between 2005 and 2006 [113].

Diabetes is a major risk factor for cardiovascular disease. Current recommendations for adults state that the added cardiovascular disease risk associated with diabetes is equivalent to that of a previous myocardial infarction. A recent report of more than 8000 long-term survivors found that these survivors are nearly twice as likely to report having diabetes as were their siblings [114].

Another longitudinal study of more than 200 long-term survivors found that $4 \%$ had diabetes, another $7 \%$ had impaired glucose tolerance, and another $4 \%$ had hyperinsulinemia [115]. These findings are especially worrisome given that the average age of adult long-term childhood survivors in the study was 25 years and that all were less than 40 years old, age cohorts that would otherwise would be considered at low-risk for impaired glucose metabolism. Cancer treatment-related cardiotoxicity may have left many childhood cancer survivors more vulnerable to cardiovascular disease [44]. Aggressive and early intervention is warranted to maximally reduce the risk in this population.

5.5.5. Hypertension. Hypertension is among the leading causes of cardiovascular disease. In 2008, 29\% percent of US adults were hypertensive, an increase from almost $24 \%$ in 1988-1994 [116].

Survivors of childhood cancer have a higher risk of developing hypertension compared to the general population. A study of 5,599 childhood cancer survivors and 2,936 siblings reported that survivors were more likely to report taking medication for hypertension than their siblings (OR 1.9, 95\% CI 1.6-202) [100].

In addition, a preexisting diagnosis of hypertension further increases the risk of clinically significant anthracycline cardiotoxicity [18]. Studies in older adults have shown that hypertension may work synergistically with doxorubicin increasing the risk of CHF [117]. Hershman et al. found that hypertension intensified the effect of doxorubicin on risk of CHF in older adults [118]. Further, studies in rats have shown a similar trend where hypertensive rats were more sensitive than normotensive rats to the cardiotoxic effects of doxorubicin [88, 118]. Therefore, monitoring cardiac status during and after anthracycline therapy is important, particularly in the long term, as risks for cardiovascular disease naturally increase with age.

\section{Conclusions and Directions for Research}

Effective anti-neoplastic therapies for childhood cancer are one of the great successes of modern medicine and have helped to create a large population of childhood cancer survivors. However, even years after successfully battling cancer, many survivors are burdened by the cardiotoxicity that can result from cancer therapy. There remains a growing need in both basic and clinical research to better understand the mechanisms of anthracycline cardiotoxicity, to develop effective and safe cardioprotection strategies, and to identify the risk factors for cardiac damage. Table 2 summarizes a number of the areas where further research could help to fill the current gaps in knowledge [23]. Most importantly, cardiologists and oncologists should collaborate to find a balance between the risks of cardiotoxicity and the benefits of oncologic therapy to maximize the quality of life and survival for long-term childhood cancer survivors.

\section{References}

[1] J. Li, T. D. Thompson, J. W. Miller, L. A. Pollack, and S. L. Stewart, "Cancer incidence among children and adolescents in the United States, 2001-2003," Pediatrics, vol. 121, no. 6, pp. e1470-e1477, 2008.

[2] A. Jemal, R. Siegel, E. Ward et al., "Cancer statistics," $C a-A$ Cancer Journal for Clinicians, vol. 60, pp. 277-300, 2010.

[3] L. B. Silverman, K. E. Stevenson, J. E. O’Brien et al., "Longterm results of dana-farber cancer institute all consortium protocols for children with newly diagnosed acute lymphoblastic leukemia (1985-2000)," Leukemia, vol. 24, no. 2, pp. 320-334, 2010.

[4] A. B. Mariotto, J. H. Rowland, K. R. Yabroff et al., "Long-term survivors of childhood cancers in the United States," Cancer Epidemiology Biomarkers and Prevention, vol. 18, no. 4, pp. 1033-1040, 2009.

[5] K. C. Oeffinger, A. C. Mertens, C. A. Sklar et al., "Chronic health conditions in adult survivors of childhood cancer," The New England Journal of Medicine, vol. 355, no. 15, pp. 1572-1582, 2006.

[6] A. C. Mertens, Q. Liu, J. P. Neglia et al., "Cause-specific late mortality among 5-year survivors of childhood cancer: the childhood cancer survivor study," Journal of the National Cancer Institute, vol. 100, no. 19, pp. 1368-1379, 2008.

[7] D. A. Mulrooney, M. W. Yeazel, T. Kawashima et al., "Cardiac outcomes in a cohort of adult survivors of childhood and adolescent cancer: retrospective analysis of the Childhood Cancer Survivor Study cohort," British Medical Journal, vol. 339, p. b4606, 2009.

[8] T. R. Möller, S. Garwicz, L. Barlow et al., "Decreasing late mortality among five-year survivors of cancer in childhood and adolescence: a population-based study in the Nordic countries," Journal of Clinical Oncology, vol. 19, no. 13, pp. 3173-3181, 2001.

[9] M. Tukenova, C. Guibout, O. Oberlin et al., "Role of cancer treatment in long-term overall and cardiovascular mortality after childhood cancer," Journal of Clinical Oncology, vol. 28, no. 8, pp. 1308-1315, 2010.

[10] S. E. Lipshultz and M. J. Adams, "Cardiotoxicity after childhood cancer: beginning with the end in mind," Journal of Clinical Oncology, vol. 28, no. 8, pp. 1276-1281, 2010. 
[11] S. E. Lipshultz, J. A. Alvarez, and R. E. Scully, "Anthracycline associated cardiotoxicity in survivors of childhood cancer," Heart, vol. 94, no. 4, pp. 525-533, 2008.

[12] R. C. Reulen, D. L. Winter, C. Frobisher et al., "Longterm cause-specific mortality among survivors of childhood cancer," Journal of the American Medical Association, vol. 304, no. 2, pp. 172-179, 2010.

[13] G. Levitt, A. Anazodo, M. Burch, and K. Bunch, "Cardiac or cardiopulmonary transplantation in childhood cancer survivors: an increasing need?" European Journal of Cancer, vol. 45, no. 17, pp. 3027-3034, 2009.

[14] S. E. Lipshultz, S. D. Colan, R. D. Gelber, A. R. PerezAtayde, S. E. Sallan, and S. P. Sanders, "Late cardiac effects of doxorubicin therapy for acute lymphoblastic leukemia in childhood," The New England Journal of Medicine, vol. 324, no. 12, pp. 808-815, 1991.

[15] M. J. Adams and S. E. Lipshultz, "Pathophysiology of anthracycline- and radiation-associated cardiomyopathies: implications for screening and prevention," Pediatric Blood and Cancer, vol. 44, no. 7, pp. 600-606, 2005.

[16] A. Giantris, L. Abdurrahman, A. Hinkle, B. Asselin, and S. E. Lipshultz, "Anthracycline-induced cardiotoxicity in children and young adults," Critical Reviews in Oncology/Hematology, vol. 27, no. 1, pp. 53-68, 1998.

[17] M. A. Grenier and S. E. Lipshultz, "Epidemiology of anthracycline cardiotoxicity in children and adults," Seminars in Oncology, vol. 25, no. 4, pp. 72-85, 1998.

[18] E. Barry, J. A. Alvarez, R. E. Scully, T. L. Miller, and S. E. Lipshultz, "Anthracycline-induced cardiotoxicity: course, pathophysiology, prevention and management," Expert Opinion on Pharmacotherapy, vol. 8, no. 8, pp. 1039-1058, 2007.

[19] K. Nysom, K. Holm, S. R. Lipsitz et al., "Relationship between cumulative anthracycline dose and late cardiotoxicity in childhood acute lymphoblastic leukemia," Journal of Clinical Oncology, vol. 16, no. 2, pp. 545-550, 1998.

[20] M. S. Horenstein, R. S. Vander Heide, and T. J. L'Ecuyer, "Molecular basis of anthracycline-induced cardiotoxicity and its prevention," Molecular Genetics and Metabolism, vol. 71, no. 1-2, pp. 436-444, 2000.

[21] D. Lebrecht, B. Setzer, U. P. Ketelsen, J. Haberstroh, and U. A. Walker, "Time-dependent and tissue-specific accumulation of mtDNA and respiratory chain defects in chronic doxorubicin cardiomyopathy," Circulation, vol. 108, no. 19, pp. 2423-2429, 2003.

[22] G. Minotti, P. Menna, E. Salvatorelli, G. Cairo, and L. Gianni, "Anthracyclines: molecular advances and pharmacologie developments in antitumor activity and cardiotoxicity," Pharmacological Reviews, vol. 56, no. 2, pp. 185-229, 2004.

[23] L. Gianni, E. H. Herman, S. E. Lipshultz, G. Minotti, N. Sarvazyan, and D. B. Sawyer, "Anthracycline cardiotoxicity: from bench to bedside," Journal of Clinical Oncology, vol. 26, no. 22, pp. 3777-3784, 2008.

[24] T. Šimůnek, M. Štěrba, O. Popelová, M. Adamcová, R. Hrdina, and V. Gerši, "Anthracycline-induced cardiotoxicity: overview of studies examining the roles of oxidative stress and free cellular iron," Pharmacological Reports, vol. 61, no. 1, pp. 154-171, 2009.

[25] K. Nicolay, R. van der Neut, J. J. Fok, and B. de Kruijff, "Effects of adriamycin on lipid polymorphism in cardiolipincontaining model and mitochondrial membranes," Biochimica et Biophysica Acta, vol. 819, no. 1, pp. 55-65, 1985.
[26] R. C. F. Leonard, S. Williams, A. Tulpule, A. M. Levine, and S. Oliveros, "Improving the therapeutic index of anthracycline chemotherapy: focus on liposomal doxorubicin (Myocet ${ }^{\mathrm{TM}}$ )," Breast, vol. 18, no. 4, pp. 218-224, 2009.

[27] N. Ashley and J. Poulton, "Mitochondrial DNA is a direct target of anti-cancer anthracycline drugs," Biochemical and Biophysical Research Communications, vol. 378, no. 3, pp. 450-455, 2009.

[28] K. B. Wallace, "Doxorubicin-induced cardiac mitochondrionopathy," Pharmacology and Toxicology, vol. 93, no. 3, pp. 105-115, 2003.

[29] K. L. Thompson, B. A. Rosenzweig, J. Zhang et al., "Early alterations in heart gene expression profiles associated with doxorubicin cardiotoxicity in rats," Cancer Chemotherapy and Pharmacology, vol. 66, no. 2, pp. 303-314, 2010.

[30] J. H. Doroshow, G. Y. Locker, and C. E. Myers, "Enzymatic defenses of the mouse heart against reactive oxygen metabolites. Alterations produced by doxorubicin," Journal of Clinical Investigation, vol. 65, no. 1, pp. 128-135, 1980.

[31] H. Ito, S. C. Miller, M. E. Billingham et al., "Doxorubicin selectively inhibits muscle gene expression in cardiac muscle cells in vivo and in vitro," Proceedings of the National Academy of Sciences of the United States of America, vol. 87, no. 11, pp. 4275-4279, 1990.

[32] X. Peng, B. Chen, C. C. Lim, and D. B. Sawyer, "The cardiotoxicology of anthracycline chemotherapeutics: translating molecular mechanism into preventative medicine," Molecular Interventions, vol. 5, no. 3, pp. 163-171, 2005.

[33] B. Chen, X. Peng, L. Pentassuglia, C. C. Lim, and D. B. Sawyer, "Molecular and cellular mechanisms of anthracycline cardiotoxicity," Cardiovascular Toxicology, vol. 7, no. 2, pp. 114-121, 2007.

[34] A. De Angelis, E. Piegari, D. Cappetta et al., "Anthracycline cardiomyopathy is mediated by depletion of the cardiac stem cell pool and is rescued by restoration of progenitor cell function," Circulation, vol. 121, no. 2, pp. 276-292, 2010.

[35] B. Kalyanaraman, J. Joseph, S. Kalivendi, S. Wang, E. Konorev, and S. Kotamraju, "Doxorubicin-induced apoptosis: implications in cardiotoxicity," Molecular and Cellular Biochemistry, vol. 234-235, pp. 119-124, 2002.

[36] R. Jurcut, H. Wildiers, J. Ganame, J. D’hooge, R. Paridaens, and J. U. Voigt, "Detection and monitoring of cardiotoxicity-what does modern cardiology offer?" Supportive Care in Cancer, vol. 16, no. 5, pp. 437-445, 2008.

[37] P. Rusconi, O. Gómez-Marín, M. Rossique-González et al., "Carvedilol in children with cardiomyopathy: 3-Year experience at a single institution," Journal of Heart and Lung Transplantation, vol. 23, no. 7, pp. 832-838, 2004.

[38] S. Lowis, I. Lewis, A. Elsworth et al., "A phase I study of intravenous liposomal daunorubicin (DaunoXome) in paediatric patients with relapsed or resistant solid tumours," British Journal of Cancer, vol. 95, no. 5, pp. 571-580, 2006.

[39] D. Lebrecht, A. Kokkori, U. P. Ketelsen, B. Setzer, and U. A. Walker, "Tissue-specific mtDNA lesions and radicalassociated mitochondrial dysfunction in human hearts exposed to doxorubicin," Journal of Pathology, vol. 207, no. 4, pp. 436-444, 2005.

[40] M. Ryberg, D. Nielsen, G. Cortese, G. Nielsen, T. Skovsgaard, and P. K. Andersen, "New insight into epirubicin cardiac toxicity: competing risks analysis of 1097 breast cancer patients," Journal of the National Cancer Institute, vol. 100, no. 15 , pp. 1058-1067, 2008. 
[41] M. Tokarska-Schlattner, M. Zaugg, C. Zuppinger, T. Wallimann, and U. Schlattner, "New insights into doxorubicininduced cardiotoxicity: the critical role of cellular energetics," Journal of Molecular and Cellular Cardiology, vol. 41, no. 3, pp. 389-405, 2006.

[42] S. E. Lipshultz, R. E. Scully, and H. M. Smith, "Serum cardiovascular growth factors during doxorubicin chemotherapy in children with leukemia," in Proceedings of the 5th World Congress of Paediatric Cardiology and Cardiac Surgery (PCCS '09), Cairns, Australia, June 2009, Cardiomyopathy Poster Session. PCCS2009 Program page 133.

[43] D. D. Von Hoff, M. Rozencweig, and M. Layard, "Daunomycin induced cardiotoxicity in children and adults. A review of 110 cases," American Journal of Medicine, vol. 62, no. 2, pp. 200-208, 1977.

[44] S. E. Lipshultz, S. R. Lipsitz, T. L. Miller et al., "Late cardiac status in long-term survivors of childhood high-risk all 8 years after continuous or bolus infusion of doxorubicin: the DFCI Childhood ALL 91-01 Randomized Trial," Journal of Clinical Oncology, vol. 28, no. 15, supplement, p. 9513, 2010.

[45] S. E. Lipshultz, N. Rifai, S. E. Sallan et al., "Predictive value of cardiac troponin $\mathrm{T}$ in pediatric patients at risk for myocardial injury," Circulation, vol. 96, no. 8, pp. 2641-2648, 1997.

[46] L. Wang and R. Weinshilboum, "Thiopurine S-methyltransferase pharmacogenetics: insights, challenges and future directions," Oncogene, vol. 25, no. 11, pp. 1629-1638, 2006.

[47] S. Deng and L. Wojnowski, "Genotyping the risk of anthracycline-induced cardiotoxicity," Cardiovascular Toxicology, vol. 7, no. 2, pp. 129-134, 2007.

[48] J. G. Blanco, W. M. Leisenring, V. M. Gonzalez-Covarrubias et al., "Genetic polymorphisms in the carbonyl reductase 3 gene CBR3 and the $\mathrm{NAD}(\mathrm{P}) \mathrm{H}$ :quinone oxidoreductase 1 gene NQ01 in patients who developed anthracycline-related congestive heart failure after childhood cancer," Cancer, vol. 112, no. 12, pp. 2789-2795, 2008.

[49] C. J. Miranda, H. Makui, R. J. Soares et al., "Hfe deficiency increases susceptibility to cardiotoxicity and exacerbates changes in iron metabolism induced by doxorubicin," Blood, vol. 102, no. 7, pp. 2574-2580, 2003.

[50] J. P. Krischer, S. Epstein, D. D. Cuthbertson, A. M. Goorin, M. L. Epstein, and S. E. Lipshultz, "Clinical cardiotoxicity following anthracycline treatment for childhood cancer: the Pediatric Oncology Group experience," Journal of Clinical Oncology, vol. 15, no. 4, pp. 1544-1552, 1997.

[51] J. P. Krischer, D. D. Cuthbertson, S. Epstein, A. M. Goorin, M. L. Epstein, and S. E. Lipshultz, "Risk factors for early anthracycline clinical cardiotoxicity in children: the pediatric oncology group experience," Progress in Pediatric Cardiology, vol. 8, no. 2, pp. 83-90, 1997.

[52] "Establishing and enhancing services for childhood cancer survivors: long-term follow-up program resource guide," Children's Oncology Group, 2007, http://www.survivorshipguidelines.org/.

[53] S. E. Lipshultz, R. E. Scully, S. R. Lipsitz et al., "Assessment of dexrazoxane as a cardioprotectant in doxorubicin-treated children with high-risk acute lymphoblastic leukaemia: longterm follow-up of a prospective, randomised, multicentre trial," The Lancet Oncology, vol. 11, no. 10, pp. 950-961, 2010.

[54] D. Cardinale, M. T. Sandri, A. Colombo et al., "Prognostic value of troponin I in cardiac risk stratification of cancer patients undergoing high-dose chemotherapy," Circulation, vol. 109, no. 22, pp. 2749-2754, 2004.
[55] D. Cardinale, M. T. Sandri, A. Martinoni et al., "Left ventricular dysfunction predicted by early troponin I release after high-dose chemotherapy," Journal of the American College of Cardiology, vol. 36, no. 2, pp. 517-522, 2000.

[56] S. E. Lipshultz, J. C. L. Wong, S. R. Lipsitz et al., "Frequency of clinically unsuspected myocardial injury at a children's hospital," American Heart Journal, vol. 151, no. 4, pp. 916922, 2006.

[57] E. H. Herman, J. Zhang, S. E. Lipshultz et al., "Correlation between serum levels of cardiac troponin-T and the severity of the chronic cardiomyopathy induced by doxorubicin," Journal of Clinical Oncology, vol. 17, no. 7, pp. 2237-2243, 1999.

[58] S. E. Lipshultz, N. Rifai, V. M. Dalton et al., "The effect of dexrazoxane on myocardial injury in doxorubicin-treated children with acute lymphoblastic leukemia," The New England Journal of Medicine, vol. 351, no. 2, pp. 145-153, 2004.

[59] S. E. Lipshultz, T. L. Miller, and R. E. Scully, "Diagnostic value of cardiac troponin $\mathrm{T}, \mathrm{N}$-terminal pro-brain natriuretic peptide, and high-sensitivity C-reactive protein during Doxorubicin therapy in children with acute lymphoblastic 6 leukemia," Circulation, vol. 122, no. 21, supplement, A20432 2010.

[60] A. Martinez-Rumayor, A. M. Richards, J. C. Burnett, and J. L. Januzzi, "Biology of the natriuretic peptides," American Journal of Cardiology, vol. 101, no. 3, pp. S3-S8, 2008.

[61] T. J. Wang, M. G. Larson, D. Levy et al., "Plasma natriuretic peptide levels and the risk of cardiovascular events and death," The New England Journal of Medicine, vol. 350, no. 7, pp. 655-663, 2004.

[62] C. Kragelund, B. Grønning, L. Køber, P. Hildebrandt, and R. Steffensen, "N-terminal pro-B-type natriuretic peptide and long-term mortality in stable coronary heart disease," The New England Journal of Medicine, vol. 352, no. 7, pp. 666675, 2005.

[63] J. Grewal, R. S. McKelvie, H. Persson et al., "Usefulness of Nterminal pro-brain natriuretic peptide and brain natriuretic peptide to predict cardiovascular outcomes in patients with heart failure and preserved left ventricular ejection fraction," American Journal of Cardiology, vol. 102, no. 6, pp. 733-737, 2008.

[64] S. Black, I. Kushner, and D. Samols, "C-reactive protein,” The Journal of Biological Chemistry, vol. 279, no. 47, pp. 4848748490, 2004.

[65] C. Ratnasamy, D. D. Kinnamon, S. E. Lipshultz et al., "Associations between neurohormonal and inflammatory activation and heart failure in children," Progress in Pediatric Cardiology, vol. 24, pp. 81-82, 2007.

[66] S. K. Singh, M. V. Suresh, B. Voleti, and A. Agrawal, "The connection between C-reactive protein and atherosclerosis," Annals of Medicine, vol. 40, no. 2, pp. 110-120, 2008.

[67] S. E. Lipshultz, S. R. Lipsitz, A. S. Hinkle et al., "Cardiovascular status, subsequent risk, and associated factors in longterm survivors of childhood cancer in a population-based NCI study," Circulation, vol. 112, supplement 2, p. 476, 2005.

[68] E. Petricoin, M. M. Ross, and W. Zhou, "Candidate serum biomarkers of doxorubicin-induced cardiotoxicity in pediatric acute lymphoblastic leukemia assessed by nanoparticlecapture mass spectrometry," Journal of Clinical Oncology, vol. 28, p. 9528, 2010. 
[69] S. E. Lipshultz, S. R. Lipsitz, S. E. Sallan et al., "Chronic progressive cardiac dysfunction years after doxorubicin therapy for childhood acute lymphoblastic leukemia," Journal of Clinical Oncology, vol. 23, no. 12, pp. 2629-2636, 2005.

[70] S. E. Lipshultz, S. R. Lipsitz, S. M. Mone et al., "Female sex and higher drug dose as risk factors for late cardiotoxic effects of doxorubicin therapy for childhood cancer," The New England Journal of Medicine, vol. 332, no. 26, pp. 1738 1743, 1995.

[71] S. E. Lipshultz and S. D. Colan, "Cardiovascular trials in long-term survivors of childhood cancer," Journal of Clinical Oncology, vol. 22, no. 5, pp. 769-773, 2004.

[72] K. Sorensen, G. A. Levitt, C. Bull, I. Dorup, and I. D. Sullivan, "Late anthracycline cardiotoxicity after childhood cancer: a prospective longitudinal study," Cancer, vol. 97, no. 8, pp. 1991-1998, 2003.

[73] J. Ganame, P. Claus, A. Uyttebroeck et al., "Myocardial dysfunction late after low-dose anthracycline treatment in asymptomatic pediatric patients," Journal of the American Society of Echocardiography, vol. 20, no. 12, pp. 1351-1358, 2007.

[74] K. Nysom, S. D. Colan, and S. E. Lipshultz, "Late cardiotoxicity following anthracycline therapy for childhood cancer," Progress in Pediatric Cardiology, vol. 8, no. 3, pp. 121-138, 1998.

[75] M. A. Schorin, S. Blattner, R. D. Gelber et al., "Treatment of childhood acute lymphoblastic leukemia: results of Dana- Farber Cancer Institute/Children's Hospital acute lymphoblastic leukemia consortium protocol 85-01," Journal of Clinical Oncology, vol. 12, no. 4, pp. 740-747, 1994.

[76] J. M. Fulbright, W. Huh, P. Anderson, and J. Chandra, "Can anthracycline therapy for pediatric malignancies be less cardiotoxic?” Current Oncology Reports, vol. 12, no. 6, pp. 411-419, 2010.

[77] A. A. Gabizon, O. Lyass, G. J. Berry, and M. Wildgust, "Cardiac safety of pegylated liposomal doxorubicin (Doxil@/Caelyx@) demonstrated by endomyocardial biopsy in patients with advanced malignancies," Cancer Investigation, vol. 22, no. 5, pp. 663-669, 2004.

[78] N. M. Marina, D. Cochrane, E. Harney et al., "Dose escalation and pharmacokinetics of pegylated liposomal doxorubicin (Doxil) in children with solid tumors: a pediatric oncology group study," Clinical Cancer Research, vol. 8, no. 2, pp. 413-418, 2002.

[79] G. A. Levitt, I. Dorup, K. Sorensen, and I. Sullivan, "Does anthracycline administration by infusion in children affect late cardiotoxicity?" British Journal of Haematology, vol. 124, no. 4, pp. 463-468, 2004.

[80] M. Gupta, P. G. Steinherz, N. K. Cheung, and L. Steinherz, "Late cardiotoxicity after bolus versus infusion anthracycline therapy for childhood cancers," Medical and Pediatric Oncology, vol. 40, no. 6, pp. 343-347, 2003.

[81] K. A. Wouters, L. C. M. Kremer, T. L. Miller, E. H. Herman, and S. E. Lipshultz, "Protecting against anthracyclineinduced myocardial damage: a review of the most promising strategies," British Journal of Haematology, vol. 131, no. 5, pp. 561-578, 2005.

[82] S. E. Lipshultz, A. L. Giantris, S. R. Lipsitz et al., "Doxorubicin administration by continuous infusion is not cardioprotective: the Dana-Farber 91-01 acute lymphoblastic leukemia protocol," Journal of Clinical Oncology, vol. 20, no. 6, pp. 1677-1682, 2002.
[83] S. E. Lipshultz, "Dexrazoxane for protection against cardiotoxic effects of anthracyclines in children," Journal of Clinical Oncology, vol. 14, no. 2, pp. 328-331, 1996.

[84] C. K. Tebbi, W. B. London, D. Friedman et al., "Dexrazoxaneassociated risk for acute myeloid leukemia/myelodysplastic syndrome and other secondary malignancies in pediatric Hodgkin's disease," Journal of Clinical Oncology, vol. 25, no. 5, pp. 493-500, 2007.

[85] S. E. Lipshultz, S. R. Lipsitz, and E. J. Orav, "Dexrazoxaneassociated risk for secondary malignancies in pediatric Hodgkin's disease: a claim without compelling evidence," Journal of Clinical Oncology, vol. 25, no. 21, p. 3179, 2007, author reply 3180 .

[86] K. Hellmann, "Dexrazoxane-associated risk for secondary malignancies in pediatric Hodgkin's disease: a claim without evidence," Journal of Clinical Oncology, vol. 25, no. 29, pp. 4689-4690, 2007.

[87] E. V. Barry, L. M. Vrooman, S. E. Dahlberg et al., "Absence of secondary malignant neoplasms in children with highrisk acute lymphoblastic leukemia treated with dexrazoxane," Journal of Clinical Oncology, vol. 26, no. 7, pp. 1106-1111, 2008.

[88] E. Herman, A. Knapton, J. Zhang, H. Hiraragi, and S. E. Lipshultz, "Gender is a factor that can impact the severity of doxorubicin (DXR) toxicity in spontaneously hypertensive rats (SHR)," The FASEB Journal, vol. 22, p. 719.6, 2008.

[89] R. V. Williams, L. Y. Tani, and R. E. Shaddy, "Intermediate effects of treatment with metoprolol or carvedilol in children with left ventricular systolic dysfunction," Journal of Heart and Lung Transplantation, vol. 21, no. 8, pp. 906-909, 2002.

[90] P. A. Thompson, G. L. Rosner, K. K. Matthay et al., "Impact of body composition on pharmacokinetics of doxorubicin in children: a Glaser Pediatric Research Network study," Cancer Chemotherapy and Pharmacology, vol. 64, no. 2, pp. 243-251, 2009.

[91] E. G. Schuetz, K. N. Furuya, and J. D. Schuetz, "Interindividual variation in expression of P-glycoprotein in normal human liver and secondary hepatic neoplasms," Journal of Pharmacology and Experimental Therapeutics, vol. 275, no. 2, pp. 1011-1018, 1995.

[92] D. Belhani, L. Fanton, F. Vaillant et al., "Cardiac lesions induced by testosterone: protective effects of dexrazoxane and trimetazidine," Cardiovascular Toxicology, vol. 9, no. 2, pp. 64-69, 2009.

[93] L. C. M. Kremer, E. C. van Dalen, M. Offringa, and P. A. Voûte, "Frequency and risk factors of anthracycline-induced clinical heart failure in children: a systematic review," Annals of Oncology, vol. 13, no. 4, pp. 503-512, 2002.

[94] J. M. LeClerc, A. L. Billett, R. D. Gelber et al., "Treatment of childhood acute lymphoblastic leukemia: results of DanaFarber ALL Consortium Protocol 87-01," Journal of Clinical Oncology, vol. 20, no. 1, pp. 237-246, 2002.

[95] S. E. Lipshultz, J. D. Wilkinson, S. E. Messiah, and T. L. Miller, "Clinical research directions in pediatric cardiology," Current Opinion in Pediatrics, vol. 21, no. 5, pp. 585-593, 2009.

[96] C. L. Ogden, M. D. Carroll, L. R. Curtin, M. A. McDowell, C. J. Tabak, and K. M. Flegal, "Prevalence of overweight and obesity in the United States, 1999-2004," Journal of the American Medical Association, vol. 295, no. 13, pp. 15491555, 2006.

[97] R. C. Whitaker, J. A. Wright, M. S. Pepe, K. D. Seidel, and W. H. Dietz, "Predicting obesity in young adulthood from childhood and parental obesity," The New England Journal of Medicine, vol. 337, no. 13, pp. 869-873, 1997. 
[98] S. E. Messiah, K. L. Arheart, B. Luke, S. E. Lipshultz, and T. L. Miller, "Relationship between body mass index and metabolic risk factors among US 8- to 14-year olds, 19992002," Journal of Pediatrics, vol. 153, no. 2, pp. 215-221, 2008.

[99] S. R. Daniels, M. S. Jacobson, B. W. McCrindle, R. H. Eckel, and B. M. Sanner, "American heart association childhood obesity: research summit," Circulation, vol. 119, no. 15, pp. 2114-2123, 2009.

[100] L. R. Meacham, J. G. Gurney, A. C. Mertens et al., "Body mass index in long-term adult survivors of childhood cancer: a report of the childhood cancer survivor study," Cancer, vol. 103, no. 8, pp. 1730-1739, 2005.

[101] P. C. Nathan, V. Jovcevska, K. K. Ness et al., "The prevalence of overweight and obesity in pediatric survivors of cancer," Journal of Pediatrics, vol. 149, no. 4, pp. 518-525.e2, 2006.

[102] T. L. Miller, S. R. Lipsitz, G. Lopez-Mitnik et al., "Characteristics and determinants of adiposity in pediatric cancer survivors," Cancer Epidemiology Biomarkers and Prevention, vol. 19, no. 8, pp. 2013-2022, 2010.

[103] B. I. Razzouk, S. R. Rose, S. Hongeng et al., "Obesity in survivors of childhood acute lymphoblastic leukemia and lymphoma," Journal of Clinical Oncology, vol. 25, no. 10, pp. 1183-1189, 2007.

[104] T. M. McCambridge, D. T. Bernhardt, J. S. Brenner et al., "Active healthy living: prevention of childhood obesity through increased physical activity," Pediatrics, vol. 117, no. 5, pp. 1834-1842, 2006.

[105] US Department of Health and Human Services (USDHHS), Physical Activity Guidelines Advisory Committee Report, 2008, US Department of Health and Human Services, Washington, DC, USA, 2008.

[106] K. K. Ness, W. M. Leisenring, S. Huang et al., "Predictors of inactive lifestyle among adult survivors of childhood cancer," Cancer, vol. 115, no. 9, pp. 1984-1994, 2009.

[107] C. L. Cox, M. Montgomery, K. C. Oeffinger et al., "Promoting physical activity in childhood cancer survivors," Cancer, vol. 115, no. 3, pp. 642-654, 2009.

[108] R. Doll and R. Peto, "Mortality in relation to smoking: 20 years' observations on male British doctors," British Medical Journal, vol. 2, no. 6051, pp. 1525-1536, 1976.

[109] S. A. Clarke and C. Eiser, "Health behaviours in childhood cancer survivors: a systematic review," European Journal of Cancer, vol. 43, no. 9, pp. 1373-1384, 2007.

[110] Centers for Disease Control and Prevention (CDC), "Cigarette smoking among adults and trends in smoking cessation-United States, 2008," Morbidity and Mortality Weekly Report, vol. 58, pp. 1227-1232, 2009.

[111] K. Emmons, F. P. Li, J. Whitton et al., "Predictors of smoking initiation and cessation among childhood cancer survivors: a report from the Childhood Cancer Survivor Study," Journal of Clinical Oncology, vol. 20, no. 6, pp. 1608-1616, 2002.

[112] K. M. Emmons, E. Puleo, A. Mertens, E. R. Gritz, L. Diller, and F. P. Li, "Long-term smoking cessation outcomes among childhood cancer survivors in the partnership for health study," Journal of Clinical Oncology, vol. 27, no. 1, pp. 52-60, 2009.

[113] C. C. Cowie, K. F. Rust, E. S. Ford et al., "Full accounting of diabetes and pre-diabetes in the U.S. population in 19881994 and 2005-2006," Diabetes Care, vol. 32, no. 2, pp. 287294, 2009.

[114] L. R. Meacham, C. A. Sklar, S. Li et al., "Diabetes mellitus in long-term survivors of childhood cancer-increased risk associated with radiation therapy: a report for the childhood cancer survivor study," Archives of Internal Medicine, vol. 169, no. 15, pp. 1381-1388, 2009.

[115] K. A. Neville, R. J. Cohn, K. S. Steinbeck, K. Johnston, and J. L. Walker, "Hyperinsulinemia, impaired glucose tolerance, and diabetes mellitus in survivors of childhood cancer: prevalence and risk factors," Journal of Clinical Endocrinology and Metabolism, vol. 91, no. 11, pp. 4401-4407, 2006.

[116] B. M. Egan, Y. Zhao, and R. N. Axon, "US trends in prevalence, awareness, treatment, and control of hypertension, 1988-2008," Journal of the American Medical Association, vol. 303, no. 20, pp. 2043-2050, 2010.

[117] E. H. Herman, A. N. El-Hage, V. J. Ferrans, and B. Ardalan, "Comparison of the severity of the chronic cardiotoxicity produced by doxorubicin in normotensive and hypertensive rats," Toxicology and Applied Pharmacology, vol. 78, no. 2, pp. 202-214, 1985.

[118] D. L. Hershman, R. B. McBride, A. Eisenberger, Y. T. Wei, V. R. Grann, and J. S. Jacobson, "Doxorubicin, cardiac risk factors, and cardiac toxicity in elderly patients with diffuse Bcell non-Hodgkin's lymphoma," Journal of Clinical Oncology, vol. 26, no. 19, pp. 3159-3165, 2008. 


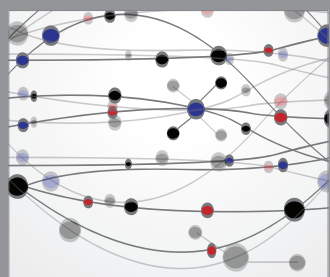

The Scientific World Journal
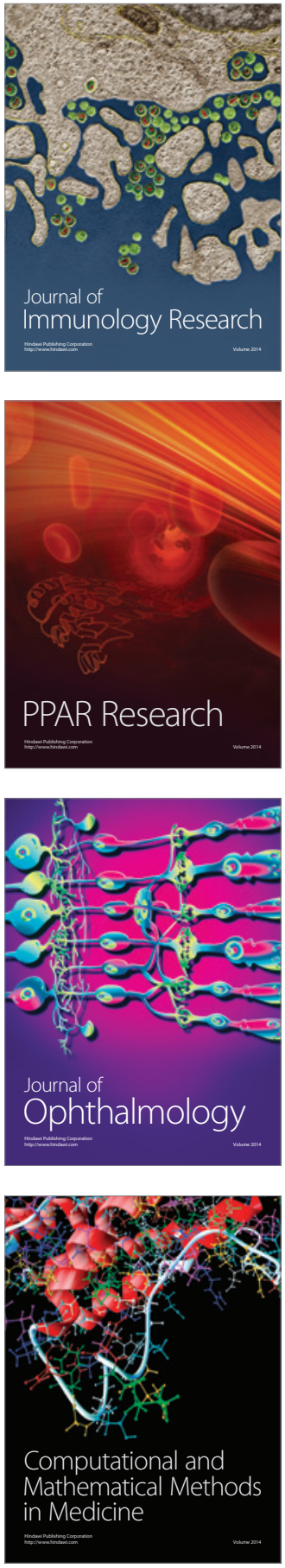

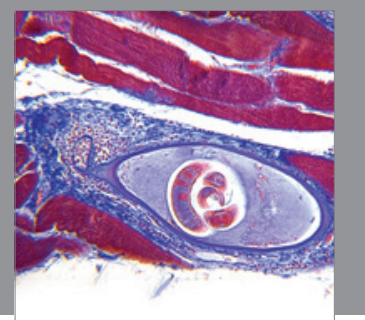

Gastroenterology

Research and Practice
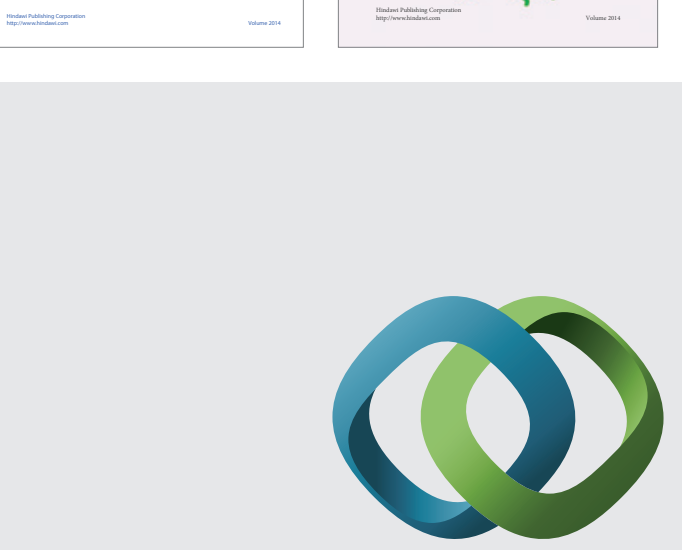

\section{Hindawi}

Submit your manuscripts at

http://www.hindawi.com
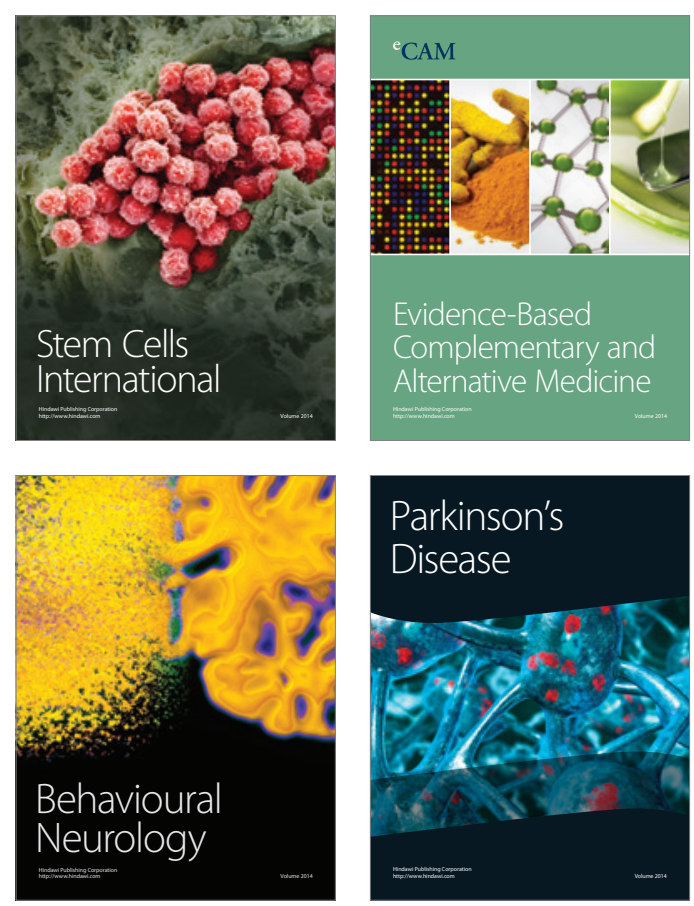

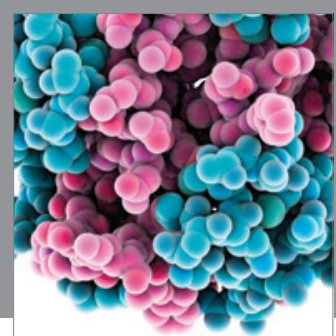

Journal of
Diabetes Research

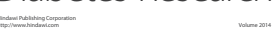

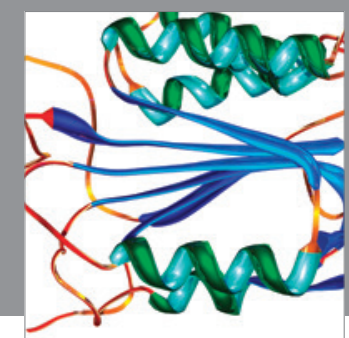

Disease Markers
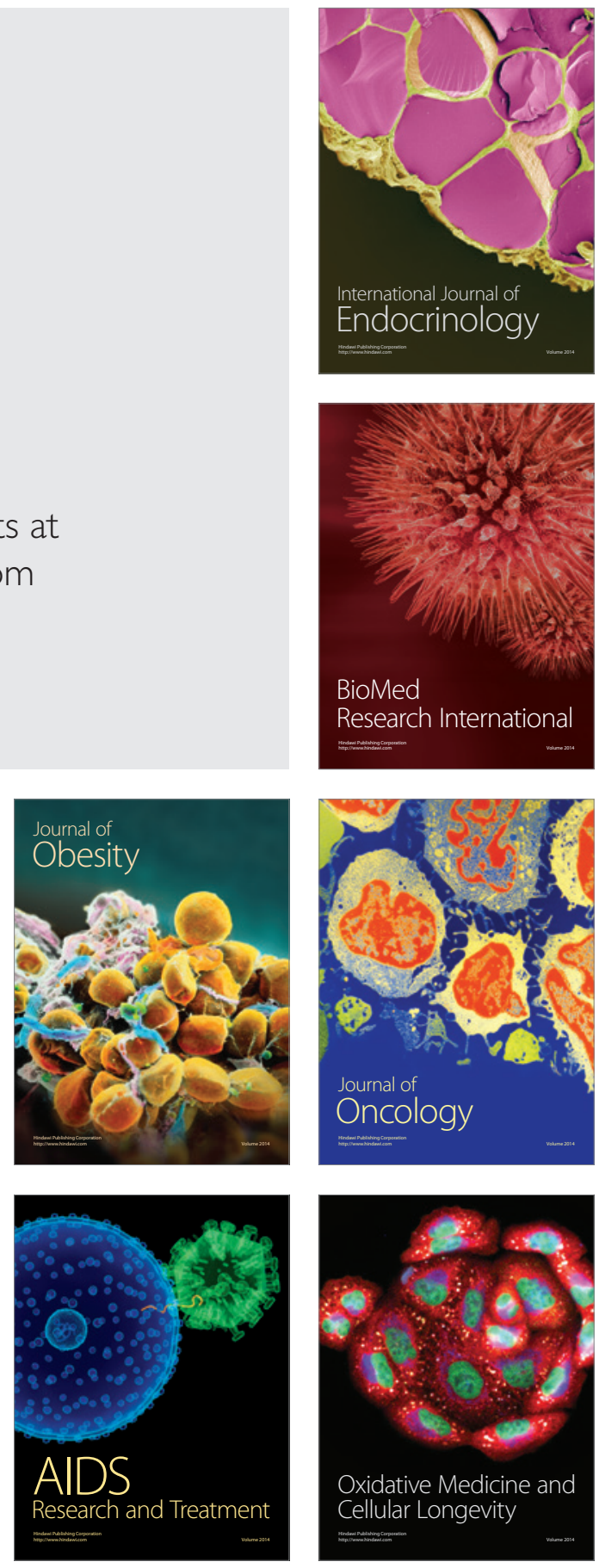